\title{
Combined Circuit Model for a Four Quadrant Operating Luo- Converter
}

\author{
Vallejo, Jefferson ${ }^{* *(D)}$; Benavides, Vanessa ${ }^{1}$ (iD) Pozo, Marcelo ${ }^{1}$ (D)

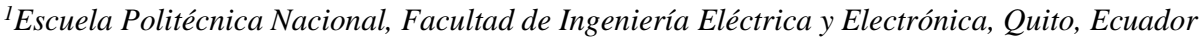

\begin{abstract}
This work presents a combined circuit, as a new methodology, for a four-quadrant operation converter using LUO's configuration based on the model proposed by Luo and Hong Ye. The combination conjugates two different circuits, each one works for controlling two of the four quadrants or modes respectively. Additionally, this paper presents simulation results for the proposed system in order to verify its characteristics and functionality.
\end{abstract}

Keywords: Luo DC/DC converter, four quadrant operation, open loop speed control for a DC motor.

\section{Modelo de Circuito Combinado Para Operación en Cuatro Cuadrantes, Convertidor de Luo}

\begin{abstract}
Resumen: Este trabajo presenta un circuito combinado, como una nueva metodología para uso de convertidores para operación en cuatro cuadrantes que utilizan la configuración de LUO, basado en el modelo propuesto por Luo y Hong Ye. La combinación combina dos circuitos diferentes, cada uno funciona para controlar dos de los cuatro cuadrantes o modos, respectivamente. Además, este documento presenta resultados de simulación para el sistema propuesto con el fin de verificar sus características y funcionalidad.
\end{abstract}

Palabras clave: Convertidor DC / DC de Luo, operación en cuatro cuadrantes, control de velocidad en circuito abierto para un motor DC.

\section{INTRODUCTION}

DC/DC converters have been used in many industrial applications which in general perform single quadrant operation. Traditional models like buck, boost and buck-boost converters (Pasha, Jayakumar, \& Thiruvonasundari, 2017) have some applications oriented, mostly, to electrical power generations, photovoltaic and renewable energy sources (Chilambarasan, Ramesh, \& Sujatha, 2014) (Saradha, Mrudhulaa, Priyadharshini, Seyezhai, \& Mrdula, 2018) (Prasanna, Kirubakaran, Rahulkumar, \& Rudhran, 2015) (Elavarasu \& Christober, 2018), power regulation (Jayachandran, Krishnaxwamy, Anbazhagan, \& Dhandapanl, 2015) and energy storage systems (Manikandan \& Vadivel, 2013) (Sanjeevikumar \& Rajambal, 2008).

However, the development of circuits capable of operating in four quadrants has become a necessity, especially in applications with smart grids, where it is necessary to control the charge and discharge of batteries or in the case of electric vehicles, where it is necessary to control the direction of the rotor axis in acceleration or braking state of a DC motor.

Luo-converters are an example of DC-DC power conversion circuits developed to perform positive to positive DC-DC voltage increasing conversion with high efficiency and nearzero output voltage and current ripples (Luo F. L., 1997).
The proposed LUO circuit depends on two semiconductors used as switches which are driven by a type of PWM signals with constant switching frequency controlled independently. A 4-pole double state switch (4PDS) is used for changing from forward and reverse states.

Each mode is controlled by one switch. Each state determines the output current path (Sujatha, Chilambarasan, \& Ramesh, 2015), and to determine the direction of the rotor axis in acceleration or braking state. Multiple motor characteristics have been considered in the simulation tests, in order that the future implementation will be more reliable.

Free quadrant change is available, but it is necessary to consider events like overcurrent in the entrance circuit loop and polarity change in the capacitor. Thus, it is important to determine safe conduction duty ranges to ensure system stability and integrity of the circuit elements, all depends on the characteristics of the loads. In this project, test results are presented for a DC motor load.

The difference between this work and the original proposed by Luo and Hong Ye in (Luo \& Ye, Chapter 7 - Multiple quadrant operating Luo-Converters, 2003) is that it presents simulation results for the combined theoretical circuit named by them as 
"Circuit 3" with a little correction discussed in the next section.

\section{COMBINED LUO-CONVERTER MODEL}

This section describes the combined circuit proposed by Luo and Hong Ye in (Luo \& Ye, Chapter 7 - Multiple quadrant operating Luo-Converters, 2003) for four quadrant operation with a small variation, instead from using a three-pole double state switch (3PDS) for the commutation, as proposed in (Luo \& Ye, Chapter 7 - Multiple quadrant operating LuoConverters, 2003) (Luo, Ye, \& Rashid, Four quadrant operating Luo-Converters, 2000), to a four-pole double state switch $(4 P D S)$ will be used as shown in Figure 1 otherwise, the proper circuit configurations will not be achieved.

The $4 P D S$ switch defines 4 poles $(A, B, C \& D)$ and two states for each pole, it means that each pole has a common pin named A, B, C or D and each one of them has two pins, one for a first state $(A 1, B 1, C 1$ or $D 1)$ and another one for a second state (A2, B2, C2 or D2).

$V 1$ is the input voltage source, $S 1$ and $S 2$ are switches that control acceleration and braking modes, $D 1$ and $D 2$ are diodes, $L 1$ is the entrance loop inductance, $R$ is a resistance, $\mathrm{C}$ is a capacitor, $V 2$ is the voltage load which represents the Electromotive Force $(E M F)$ of a DC motor or the voltage value of a Battery in the case of a battery charge application, $I_{L I}$ and $I_{L 2}$ are the currents which flow through inductors $L 1$ and $L 2$ respectively, $\delta$ is the duty cycle.

Figure 2 and Figure 3 show how the $4 P D S$ works to switch from circuit 1 to circuit 2 in order to reach the Luo-converter circuit topology for operation in Quadrants I, II and III, IV respectively.

The circuit can work in four modes or quadrants as follows:

1. Mode A (Quadrant I): Forward acceleration.

2. Mode B (Quadrant II): Brake in forward operation.

3. Mode C (Quadrant III): Reverse acceleration.

4. Mode D (Quadrant IV): Brake in reverse operation.

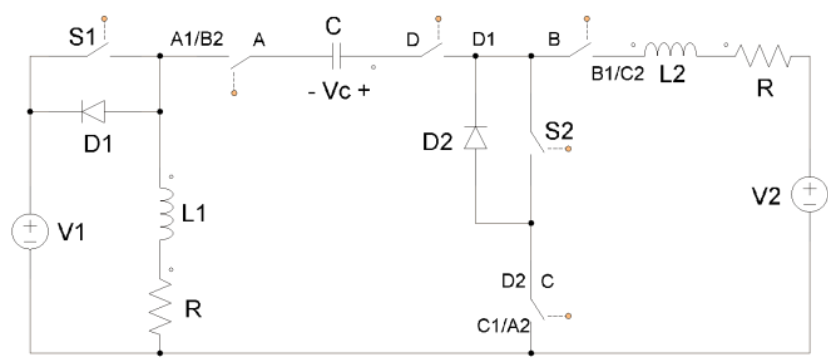

Figure 1. Combined Luo-converter circuit topology with a 4PDS switch.

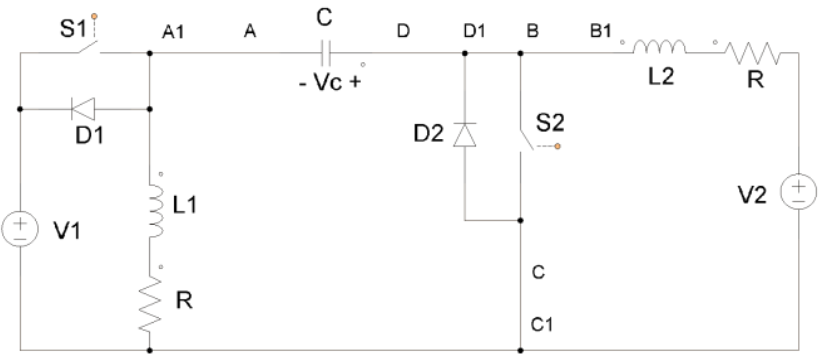

Figure 2. Luo-converter circuit topology for Quadrants I and II

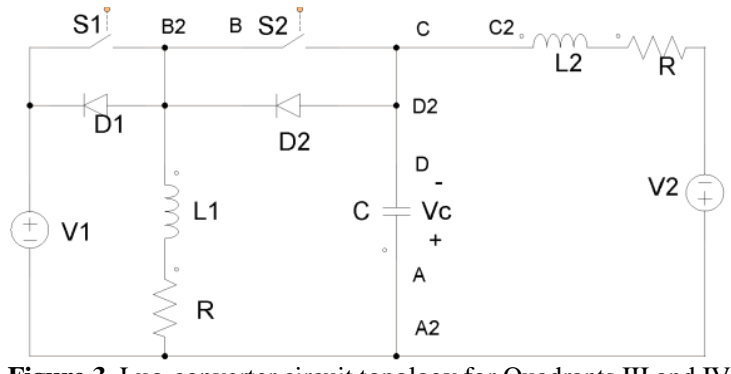

Figure 3. Luo-converter circuit topology for Quadrants III and IV

For a comprehensive review of the functionality of these circuits, as explained by Luo and Hong Ye, refer to (Luo \& Ye, Chapter 7 - Multiple quadrant operating Luo-Converters, 2003) (Luo, Ye, \& Rashid, Four quadrant operating LuoConverters, 2000).

Table 1 shows the operation mode of the circuit depending on the $4 P D S$ and the states of switches $S 1$ and $S 2$.

The considered parameters for the circuit based on calculations in (Luo \& Ye, Chapter 7 - Multiple quadrant operating LuoConverters, 2003) (Luo, Ye, \& Rashid, Four quadrant operating Luo-Converters, 2000) are: $V 1=42[V], V 2=$ $\pm 14[V], R=0,05[\Omega], L 1=L 2=0,5[\mathrm{mH}], C=$

$20[\mu \mathrm{F}]$ and $f=50[\mathrm{kHz}]$. Polarity of $V 2$ depends on the mode of operation (+) for Modes A \& B and (-) for Modes C \& D.

\begin{tabular}{|c|c|c|c|}
\hline Mode & S1 & S2 & 4PDS \\
\hline $\begin{array}{c}\text { A } \\
\text { (Quadrant I) }\end{array}$ & $\begin{array}{c}\text { PWM } \\
\text { switching }\end{array}$ & Off & $\begin{array}{l}\text { Pin A connected to pin A1 } \\
\text { Pin B connected to pin B1 } \\
\text { Pin C connected to pin C1 } \\
\text { Pin D connected to pin D1 } \\
\text { Pin A connected to pin A1 }\end{array}$ \\
\hline $\begin{array}{c}\text { B } \\
\text { (Quadrant II) }\end{array}$ & Off & $\begin{array}{c}\text { PWM } \\
\text { switching }\end{array}$ & $\begin{array}{l}\text { Pin B connected to pin B1 } \\
\text { Pin C connected to pin C1 } \\
\text { Pin D connected to pin D1 } \\
\text { Pin A connected to pin A2 }\end{array}$ \\
\hline $\begin{array}{c}\text { C } \\
\text { (Quadrant III) }\end{array}$ & $\begin{array}{c}\text { PWM } \\
\text { switching }\end{array}$ & Off & $\begin{array}{l}\text { Pin B connected to pin B2 } \\
\text { Pin C connected to pin C2 } \\
\text { Pin D connected to pin D2 } \\
\text { Pin A connected to pin A2 }\end{array}$ \\
\hline $\begin{array}{c}\text { D } \\
\text { (Quadrant IV) }\end{array}$ & Off & $\begin{array}{c}\text { PWM } \\
\text { switching }\end{array}$ & $\begin{array}{l}\text { Pin B connected to pin B2 } \\
\text { Pin C connected to pin C2 } \\
\text { Pin D connected to pin D2 }\end{array}$ \\
\hline
\end{tabular}

\section{SIMULATION RESULTS}

\subsection{Current behaviour for a \pm V2 load.}

If $V 2$ is positive and current $I L 2$ is increased positively, it means that the circuit is trying to get the acceleration state. Furthermore, if $V 2$ is positive and the current $I L 2$ is increased negatively, then it determines a positive braking mode.

For negative acceleration state, $V 2$ is negative and also the current $I L 2$ is increased negatively and negative braking state is determined by a negative $V 2$ with positively increasing of IL2.

3.2 Current behaviour for a DC motor load.

As shown in Figure 4, a DC motor is implemented as a load in the output where $V e$ represents the separately excitation 
voltage for the motor. Table 2 shows the motor parameters considered in the implementation.

Where, $R a$ is the Armature resistance, $L a$ is the Armature inductance, $R f$ is the field resistance, $L f$ is the field inductance, $V t$ is the Nominal voltage, $I a$ is the nominal current, $n$ is the nominal speed.

Figure 5 shows the motor speed and the current in the output $I_{L 2}$ in acceleration and braking modes with a DC motor load. In purple it shown the motor speed that defines positive acceleration in Figure 5a, brakes positively as shown in Figure $5 \mathrm{~b}$, accelerates negatively as shown in Figure $5 \mathrm{c}$ and brakes negatively as shown in Figure 5d. Braking is started in $\mathrm{t}=0.4$ because it depends on acceleration state.

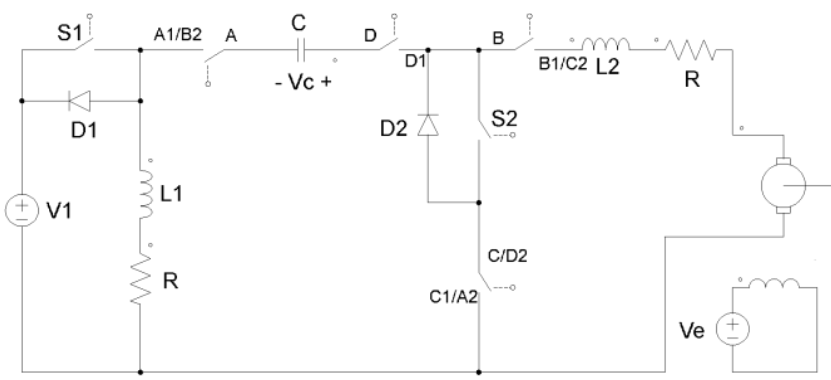

Figure 4. Combined Luo-converter circuit with a separately excited DC motor load

Table 2. DC Motor parameters

\begin{tabular}{cc} 
Parameter & Value \\
\hline $\mathrm{Ra}$ & $0,7[\Omega]$ \\
$\mathrm{La}$ & $10[\mathrm{mH}]$ \\
$\mathrm{Rf}$ & $75[\Omega]$ \\
$\mathrm{Lf}$ & $20[\mathrm{mH}]$ \\
Moment Inertia & $0,7\left[\mathrm{kgm}^{2}\right]$ \\
$\mathrm{Vt}$ & $120[\mathrm{~V}]$ \\
Ia & $10[\mathrm{~A}]$ \\
$\mathrm{n}$ & $500[\mathrm{rpm}]$ \\
If & $1,6[\mathrm{~A}]$ \\
$\mathrm{Ve}$ & $120[\mathrm{~V}]$ \\
\hline
\end{tabular}
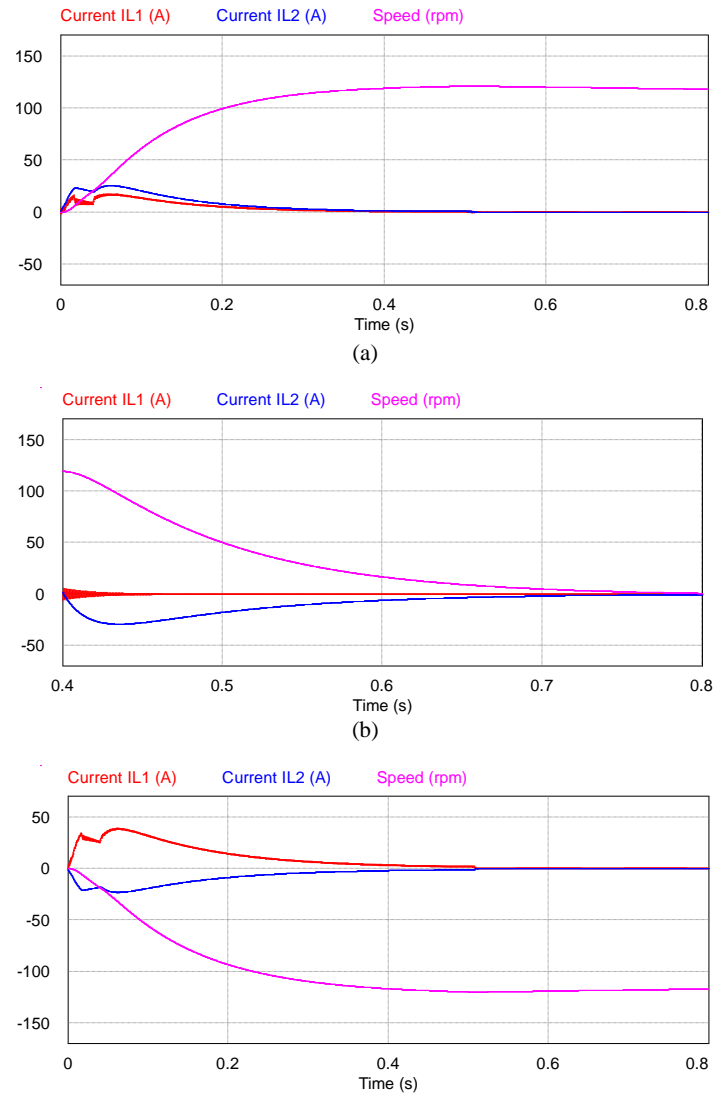

(c)

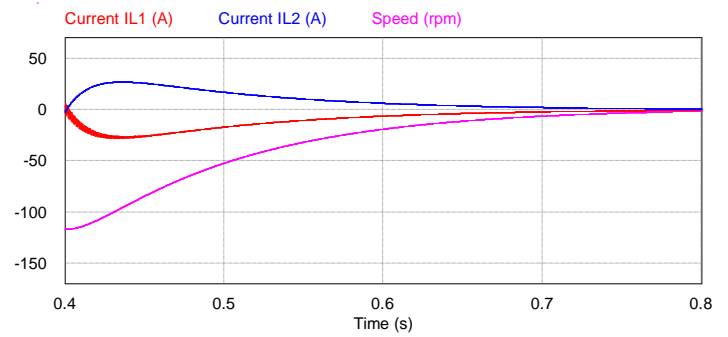

(d)

Figure 5. Speed output for a (a) motor load with $\delta=0,40$ (Mode A), (b) motor load with $\delta=0,99$ (Mode B) at $\mathrm{t}=0,4$, (c) motor load with $\delta=0,40$ (Mode C), (d) motor load with $\delta=0,99$ (Mode D) at t=0,4 (Powersim, 2016).

Duty cycle values were tested in the experimentation in order to obtain safe operation ranges. It was necessary because overcurrent values could damage the circuit and small values can make the circuit to respond extremely slow, then, the safe duty cycle range was between, $0,30<\delta<0,50$ for acceleration modes and 0,80 $<\delta<0,99$ for braking modes.

\section{CONCLUSIONS}

The proposed combined circuit model for a four-quadrant operation Luo-converter seems to be reliable for controlling a DC motor load in acceleration and braking modes. This is possible due to EMF, as a generating part of the output current increase positively or negatively depending on the operation mode.

The considered parameters for a DC motor make the circuit more reliable for a future implementation considering safe duty cycle ranges in order to protect the circuit integrity and 
stability. These ranges are, $0,30<\delta<0,50$ for acceleration modes and $0,80<\delta<0,99$ for braking modes.

It is important to consider maximum current values when suddenly changing quadrants, as these could damage circuit elements, e.g. a change from I quadrant to III quadrant over increases the input loop current.

\section{REFERENCES}

Chilambarasan, M., Ramesh, M., \& Sujatha, R. (2014). Design and simulation of LUO converter topologies for photovoltaic applications. International Journal of Applied Engineering Research, IX(23), 2-8.

Elavarasu, R., \& Christober, A. (2018). DC-DC LUO converter based smart street lighting using arduino UNO. International Journal of Innovations in Engineering and Technology (IJIET), X(1), 1-4.

Jayachandran, D., Krishnaxwamy, V., Anbazhagan, L., \& Dhandapanl, K. (2015). Modelling and analysis of voltage mode controlled LUO converter. American Journal of Applied Sciences, 1-9.

Luo, F. L. (1997). En Luo-Converters, a series of new DC-DC step-up (boost) conversion circuits (Vol. 2, págs. 882-888). Singapore.

Luo, F., \& Ye, H. (2003). Chapter 7 - Multiple quadrant operating LuoConverters. En Advanced DC-DC Converters (págs. 391-421). United States of America: CRC Press LLC.

Luo, F., Ye, H., \& Rashid, M. (2000). Four quadrant operating LuoConverters. IEEE, 1-6.

Manikandan, A., \& Vadivel, N. (2013). Design and implementation of LUO converter for electric vehicle applications. International Journal of Engineering Trends and Technology (IJETT), IV(10), 1-4.

Pasha, A., Jayakumar, N., \& Thiruvonasundari, D. (2017). Performance Analysis of Dc-Dc Converters and Comparative study of buck-boost with SLLB converter by using SPV based INC MPPT technique. International Research Journal of Engineering and Technology (IRJET), IV(8), 1-6.

Powersim. (2016). PSIM User's Guide. USA: Powersim.

Prasanna, K., Kirubakaran, D., Rahulkumar, J., \& Rudhran, A. (2015). Implementation of positive output super lift LUO converter for photovoltaic system. International Research Journal of Engineering and Technology (IRJET), II(3), 1-5.

Sanjeevikumar, P., \& Rajambal, K. (2008). Extra-High-Voltage DC-DC Boost converters topology with simple control strategy. Hindawi Publishing Corporation Modeling and Simulation in Engineering, 2008, 1-7.

Saradha, R., Mrudhulaa, P., Priyadharshini, K., Seyezhai, R., \& Mrdula, V. (2018). Development of solar dc home system using modified LUO converter. International Journal of Engineering and Advanced Technology (IJEAT), VIII(1), 1-7.

Sujatha, R., Chilambarasan, M., \& Ramesh, M. (2015). Design and simulation of fused LUO converter. Asian Research Publishing Network (ARPN), $10(8), 2-5$.

\section{BIOGRAFÍAS}

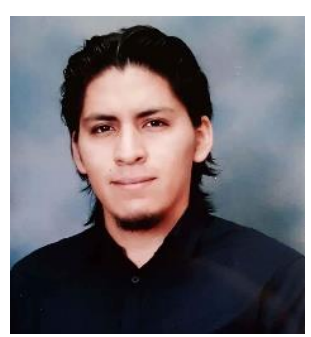

Jefferson Vallejo, was born on November 30, 1989 in Quito-Ecuador. He completed his secondary studies at "Sebastián de Benalcázar" high school in 2008. Between 2017-2019 he participated in many conferences in the National Polytechnic School (EPN) as expositor, including the "XXIX Jornadas de ingeniería Eléctrica y Electrónica" in November 2019. He currently develops his degree work at the EPN in the Electronics and Control career.

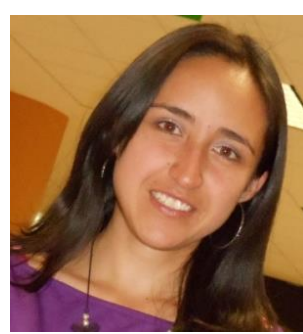

Vanessa Benavides, was born in Quito, Ecuador. Her higher studies were completed in 2011 at National Polytechnic School, obtaining the Electronics and Control Engineer degree. She served as Assistant to the Process Control Laboratory of the Department of Automation and Industrial Control (DACI) of the Faculty of Electrical and Electronic Engineering of the EPN from 2009 to 2011. Between 2011 and 2013 she dedicated herself to work in the industry. Her master's degree was held between 2013-2014, in Brazil at the Federal University of Pernambuco in Production Engineering with a mention in Operations Research. She currently works as a Full Time Professor at the National Polytechnic School (DACI).

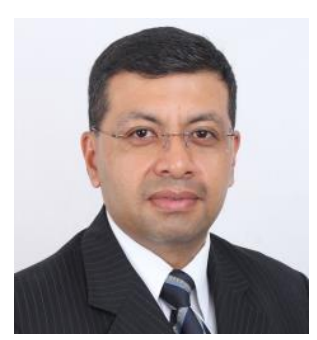

Marcelo Pozo, was born in QuitoEcuador. He graduated from the National Polytechnic School as an Electronics and Control Engineer in 1999. Thanks to a scholarship from the German Academic Exchange Service (DAAD) he studied his Master's Degree at the Technical University of Dresden-Germany obtaining the M.Sc.EE degree in September 2002. Between 2003 and 2009 he dedicated himself to work in the industry. As of September 2009, he serves as a full-time Principal Professor in the Department of Automation and Industrial Control (DACI) of the Faculty of Electrical and Electronic Engineering of the National Polytechnic School in Quito, Ecuador. Between the end of 2010 and the beginning of 2015 he completed his $\mathrm{PhD}$ project in Engineering at the University of Siegen, Germany, specializing in Power Electronics and Electronic Control of Electrical Machines. 